\title{
Elevated Psychosocial Stress at Work in Patients with Systemic Lupus Erythematosus and Rheumatoid Arthritis
}

\author{
Jutta G. Richter, Thomas Muth, Jian Li, Ralph Brinks, Gamal Chehab, Tobias Koch, \\ Johannes Siegrist, Peter Angerer, Dörte Huscher, and Matthias Schneider
}

\begin{abstract}
Objective. Psychosocial stress at work not only affects the healthy working population, but also workers with chronic diseases. We aimed to investigate the psychosocial work stress levels in patients with systemic lupus erythematosus (SLE) and rheumatoid arthritis (RA).

Methods. A cross-sectional study applied the Effort-Reward Imbalance (ERI) questionnaire - an internationally established instrument that measures work stress - to patients with SLE and RA who were capable of work and to a group of controls without these diseases. Participants were recruited through rheumatologists in private practices, hospitals, and from self-help groups by personal communication, paper-based flyers, and online advertisements. Because very few studies tested the ERI's applicability in patient groups, with a lack of evidence in patients with inflammatory rheumatic diseases, internal consistency and construct validity of the ERI measure were evaluated.

Results. Data came from 270 patients with RA and 247 with SLE, and 178 controls. Patients showed elevated psychosocial stress at work compared to controls. Across the total sample and all groups, satisfactory internal consistencies of the scales effort, reward, and overcommitment were obtained (Cronbach's alpha coefficients $>0.70$ ), and confirmatory factor analysis replicated the theoretical structure of the ERI model (goodness-of-fit index $>0.80$ ).

Conclusion. We found elevated psychosocial stress at work in patients with SLE and RA compared to controls by applying the ERI model. Despite some heterogeneity in the sample, we achieved satisfactory psychometric properties of the ERI questionnaire. Our results suggest that the ERI questionnaire is a psychometrically useful tool to be implemented in epidemiological studies of employed patients with SLE and RA. (First Release November 15 2017; J Rheumatol 2018;45:227-34; doi:10.3899/jrheum.170233)
\end{abstract}

Key Indexing Terms:

EFFORT-REWARD IMBALANCE RHEUMATOID ARTHRITIS

\section{SYSTEMIC LUPUS ERYTHEMATOSUS CONSTRUCT VALIDITY WORK STRESS}

Persons who have to cope with a chronic physical disease are generally more susceptible to the stressors of everyday life than healthy persons, given their particular need to compensate for functional limitations, pain, and discomfort ${ }^{1,2}$. This clearly holds true for a majority of patients with systemic lupus erythematosus (SLE) and rheumatoid arthritis (RA) ${ }^{1,3}$. Among the stressors of everyday life, the challenges of paid work are of primary importance. To maintain their job and to secure related rewards, people have to manage recurrent demands and adapt to changing work environments. In times of high work pressure, competition, and growing job insecurity, these challenges matter for a large number of working people ${ }^{4}$. Yet the difficulties may be particularly threatening to chronically ill persons, such as
From the Policlinic for Rheumatology and Hiller Research Unit for Rheumatology; the Institute for Occupational, Social, and Environmental Medicine, University Clinic Düsseldorf, Medical Faculty, Heinrich-Heine-University, Düsseldorf; Epidemiology Unit, German Rheumatism Research Centre, A. Leibniz Institute, Berlin, Germany. The study received unrestricted grants from the Ministry of Innovation, Science, Research and Technology of the German State of North Rhine-Westphalia, Deutsche Rheuma-Liga e.V., German LE Self-Help Community, and AbbVie Germany.

J.G. Richter, MD, PhD, Policlinic for Rheumatology and Hiller Research Unit for Rheumatology; T. Muth, MPH, PhD, Institute for Occupational, Social and Environmental Medicine, University Clinic Düsseldorf, Medical Faculty, Heinrich-Heine-University; J. Li, MD, PhD, Institute for Occupational, Social, and Environmental Medicine, University Clinic Düsseldorf, Medical Faculty, Heinrich-Heine-University; R. Brinks, PhD,
Policlinic for Rheumatology and Hiller Research Unit for Rheumatology; G. Chehab, MD, Policlinic for Rheumatology and Hiller Research Unit for Rheumatology; T. Koch, MA, MBA, Policlinic for Rheumatology and Hiller Research Unit for Rheumatology; J. Siegrist, MD, Prof., Senior Professorship, Work Stress Research; P. Angerer, MD, Prof., Institute for Occupational, Social, and Environmental Medicine, University Clinic Düsseldorf, Medical Faculty, Heinrich-Heine-University; D. Huscher, PhD, Epidemiology Unit, German Rheumatism Research Centre, A. Leibniz Institute; M. Schneider, MD, Prof., Policlinic for Rheumatology and Hiller Research Unit for Rheumatology.

Address correspondence to Dr. J.G. Richter, Policlinic for Rheumatology and Hiller Research Unit for Rheumatology, University Clinic Düsseldorf, Medical Faculty, Heinrich-Heine-University, Moorenstr. 5, 40225 Düsseldorf, Germany. E-mail: richter@rheumanet.org Accepted for publication July 24, 2017.

Personal non-commercial use only. The Journal of Rheumatology Copyright @ 2018 . All rights reserved. 
those having SLE and RA ${ }^{1,5}$. By taxing or even overtaxing their capacities, these challenges might trigger chronic psychosocial stress at work and reduce the work ability of these specific groups within the labor force $e^{1,5,6,7}$.

To our knowledge, psychosocial stress at work has rarely been analyzed among persons with SLE and RA, in comparison with employed persons who are free from these chronic diseases ${ }^{8}$. Therefore, we set out to analyze the level of stress at work in the 2 groups of patients and of "healthy" controls. To this end, one of the internationally established work stress models, effort-reward imbalance (ERI), has been included, which is fundamentally based on the notion of mutual social exchange. It posits that an imbalance between high effort spent and low reward received in turn elicits negative emotions and related psychobiological stress responses among employees, because it violates a basic norm of reciprocity in costly transactions ${ }^{9}$. Importantly, rewards include salary and wages, promotion prospects, job security, and esteem or recognition. In addition to the extrinsic component of the model (i.e., effort and reward), an intrinsic, person-related aspect termed "overcommitment" has been identified. It reflects a working person's distinct pattern of coping with demands characterized by excessive striving and an inability to withdraw from work obligations. It is hypothesized that (1) each component of the model (effort, reward, and overcommitment) exerts separate effects on health; (2) the size of effect on health produced by the combination of high effort and low reward (imbalance) exceeds the effect size produced by each single component; and (3) the personal coping pattern called "overcommitment" moderates the effect size of ERI on health (interaction term) ( $^{9,10}$

In times of increased work pressure and job insecurity in an era of globalization, this model seems particularly useful $^{10}$. However, because its measurement, the ERI questionnaire, has mainly been applied so far to healthy working populations and rarely among chronically ill employees (for exceptions, see Aboa-Éboulé, et al ${ }^{11}$ and $\mathrm{Li}$, et $a l^{12}$ ), there is a need to test its applicability in the 2 chronically ill working groups under study. Therefore, this contribution has 2 aims: first, to test the consistency, construct validity, and factorial structure of the ERI questionnaire in patients with SLE and RA, and second to compare the level of psychosocial stress at work between these 2 groups and a "healthy" control group matched by relevant sociodemographic factors. Both aims can contribute to the development and implementation of clinically useful tools of assessing and improving the work ability of persons with SLE and RA.

\section{MATERIALS AND METHODS}

Between 2006 and 2009 we conducted a cross-sectional nationwide study in Germany that focused on the effect of inflammatory rheumatic diseases (IRD) on patients' profession and work situation, and vice versa. Within this study, a set of standardized self-reported questionnaires was applied to patients with SLE and RA who were capable of work.
Patient recruitment was achieved through rheumatologists in private practices, and in community as well as university hospitals with a flyer promotion. The flyer offered patients online and paper-based study participation. For the latter, patients needed to contact the study secretary. Questionnaires were then sent by mail and after having answered the questionnaires, patients returned them in a postage-paid envelope Alternatively, patients were able to access the study online at www.gender.rheumanet.org, where online data acquisition had been established in accordance with the local data protection officer. The study Website was linked to various German health-related Websites. German self-help groups supported data acquisition through promotion in their networks. In addition, we sent out questionnaires to members of the self-help groups Deutsche Rheuma-Liga e.V.

The study protocol design required patients to recruit their own control persons whenever possible, reflecting a realistic proxy strategy. To enlarge the sample size and to gain a representative sample, the inclusion criteria were being diagnosed with one of the IRD and being capable of work, in any occupation. Sex and age did not matter. Controls' inclusion criteria were matched to those of patients: (1) not having an IRD; (2) being capable of work and having a similar workplace to the patient, as much as possible; and (3) being the same sex and similar age. During the recruitment process, some patients failed to recruit a control person; however, we still included these patients without controls as our study sample. Thus, the control group was substantially smaller than the 2 groups with rheumatic disease. In total, 247 patients with SLE, 270 patients with RA, and 178 controls were included for data analyses.

Representation of the sample was evaluated by comparison with reference data from the national database of the German Collaborative Arthritis Centers (NDB) at the German Rheumatism Research Center, an ongoing prospective study established in 1993, providing annually updated information on patients with IRD under routine rheumatologic care in a population-based setting (Table 1) ${ }^{13,14}$. Reference data were drawn from patients below retirement age $(<65 \mathrm{yrs})$ with current employment during the period from 2006 to 2009 , choosing the first available documentation for each patient within that period.

Clinical and sociodemographic data. Clinical and sociodemographic data were assessed using questions that were adapted to the case report forms of the NDB, and that are also already successfully applied in the Lupus erythematosus longterm study (LULA) ${ }^{15}$. Comorbidities were self-reported and assessed in prespecified multiple choice categories used in LULA ${ }^{15}$. For the measurement of functional capacity, the Hannover Functional Questionnaire was filled in. Values were transformed to the corresponding Health Assessment Questionnaire (HAQ) values, using the transformation described by Lautenschläger, et $a l^{16}$.

Application of the ERI questionnaire. The 23-item version of the standardized ERI questionnaire was applied to the sample measuring personal effort, reward, and overcommitment at work ${ }^{17}$.

Effort and reward questions were measured by Likert-scaled items with a 2-step response in which participants had to decide whether they agreed or disagreed with the item content. They then had to judge to what extent they were distressed by this fact on a 4-point scale. The scale "effort" was measured by the mean score of 6 questions. The scale "reward" (score derived from 11 questions) consists of 3 subscales: esteem (5 questions), job promotion (2 questions), and job security (4 questions). Sum scores of the ratings were calculated. High scores reflect great effort, reward, and overcommitment. Scale ranges are as follows: effort 6-30, reward 11-55, and overcommitment $6-24$. The subscales of the reward scale range from 5 to 25 (esteem), from 4 to 20 (promotion), and from 2 to 10 (security). According to a proposed standard procedure, an algorithm was applied to quantify the ERI at individual level (E/R ratio). This ratio is calculated by dividing the score for effort by the score for reward, adjusted for unequal numbers of items. An effort-reward ratio above 1.0 reflects ERI. Overcommitment scores (OCS) in the upper tertile indicate relevant values ${ }^{17}$.

Ethics. Study participation was voluntary for patients and controls, and was

Personal non-commercial use only. The Journal of Rheumatology Copyright (C) 2018. All rights reserved 
Table 1. Clinical and sociodemographic data of the patient groups and reference data from the national database (NDB).

\begin{tabular}{|c|c|c|c|c|c|}
\hline & $\begin{array}{l}\text { Control Group, } \\
\mathrm{n}=178\end{array}$ & $\begin{array}{l}\text { Patients with RA, } \\
\qquad n=270\end{array}$ & $\begin{array}{c}\text { Patients with SLE, } \\
\qquad \mathrm{n}=247\end{array}$ & $\begin{array}{l}\text { NDB* RA, } \\
\mathrm{n}=2788\end{array}$ & $\begin{array}{l}\text { NDB* SLE } \\
\mathrm{n}=612\end{array}$ \\
\hline Female $(\%)$ & 89.8 & 85.2 & 95.5 & 74.2 & 89.5 \\
\hline Disease duration, yrs, mean \pm SD & - & $8.8 \pm 7.9$ & $10.5 \pm 7.4$ & $6.6 \pm 7.4$ & $9.5 \pm 7.6$ \\
\hline No. comorbidities, median (IQR) & $0(0-1)^{\#}$ & $2(1-4)^{\#}$ & $2(1-4)^{\#}$ & $1(0-2)^{+}$ & $1(0-2)^{+}$ \\
\hline $\mathrm{HAQ}($ mean $\pm \mathrm{SD})$ & $0.42 \pm 0.15$ & $1.12 \pm 0.53$ & $0.78 \pm 0.44$ & $0.85 \pm 0.49$ & $0.61 \pm 0.38$ \\
\hline \multicolumn{6}{|l|}{ Marital status (\%) } \\
\hline Single/widowed/living alone & 26.3 & 31.8 & 33.1 & 24.5 & 27.5 \\
\hline Married or in marriage-like relationship & 73.7 & 68.2 & 66.9 & 76.5 & 72.5 \\
\hline \multicolumn{6}{|l|}{ Highest professional education (\%) } \\
\hline No professional education & 4.1 & 7.9 & 9.4 & 12.8 & 10.3 \\
\hline Nonacademic training & 66.7 & 70.3 & 65.8 & 63.9 & 61.6 \\
\hline White-collar worker & 92.1 & $84.8^{\S}$ & $91.9^{\S}$ & 78.6 & 86.3 \\
\hline Pain score last 7 days, $(0-10)$, median (IQR) & $0(0-1)$ & $4(3-7)$ & $3(2-5)$ & $4(2-6)$ & $2(0-5)$ \\
\hline Impairment score last 7 days, $(0-10)$, median (IQR) & $0(0-1)$ & $4(2-6)$ & $3(1-5)$ & n.a. & n.a. \\
\hline
\end{tabular}

* Data from the NDB of the German Collaborative Arthritis Centres at the German Rheumatism Research Center in Berlin, reference years 2006-2009, including only employed patients below retirement age ${ }^{13}$. " Self-reported comorbidities were assessed in multiple choice, pre-given categories only: myocardial infarction, apoplexy, arterial hypertension, diabetes, malignancies, chronic kidney disease, chronic lung disease, chronic liver disease, chronic gastrointestinal diseases, osteoporosis, depression/psychiatric diseases, fibromyalgia, venous thrombosis, degenerative joint disease, elevated blood lipids, cicatrizing skin changes. + Physician-derived comorbidities also assessed in prespecified categories only, from Albrecht, et al ${ }^{14}$. ${ }^{\S}$ Chi-square test comparing RA, respectively. SLE patients with the corresponding NDB cohorts, p < 0.05. n.a.: not available; RA: rheumatoid arthritis; SLE: systemic lupus erythematosus; IQR: interquartile range; HAQ: Health Assessment Questionnaire; BMI: body mass index.

based on informed consent. Ethical approval was obtained from the Ethics Committee of the local medical faculty (local reference no. 2564).

Statistical analyses. Data entry and management were performed using a Web-based application into a Microsoft SQL database. First, descriptive analyses were generated to describe the characteristics of the study subjects. Values are expressed as percentages for discrete variables, or as mean $\pm \mathrm{SD}$, range, interquartile range (IQR), or median for continuous variables. We used $\mathrm{R}$ (The R Foundation for Statistical Computing, version 3.2.0) for these data analyses.

Second, because of the skewed distribution of the scores of ERI scales (Shapiro-Wilk test, $\mathrm{p}<0.05$ ), medians and IQR were calculated for the complete group as well as the control group, patients with RA, and patients with SLE, respectively; then a nonparametric method, i.e., Kruskal-Wallis test, was conducted to compare the differences among the 3 groups, and pairwise 2-sided multiple comparison analyses were determined by the Dwass, Steel, Critchlow-Fligner method.

Third, as a central aspect of scale reliability, internal consistency was assessed by Cronbach's alpha coefficients for each ERI scale. Finally, factorial validity was tested by confirmatory factor analysis (CFA). Based on prior evidence of psychometric properties of ERI measure ${ }^{11,17,18,19,20,21,22,23,24,25}$, a third-order model representing the conceptual structure of the ERI theory was applied, i.e., 3 second-order factors (effort, reward, and overcommitment) loading on a third-order factor representing the latent ERI construct, while the components esteem, job security, and job promotion identified as first-order factors loading on the reward factor. Goodness of fit was assessed by several established indicators including the goodness-of-fit index (GFI), adjusted GFI (AGFI), and comparative fit index (CFI), each with values exceeding 0.90 suggesting a satisfactory fit; root mean square error of approximation (RMSEA) values below 0.08 suggested a reasonable fit to the data. Based on several earlier clinical investigations testing psychometric properties of questionnaires, it is also recommended that values of GFI, AGFI, and CFI exceeding 0.80 are to be considered acceptable 26,27 . We used SAS 9.4 for all the ERI analyses.

\section{RESULTS}

Clinical and sociodemographic data. After applying the inclusion criteria, 270 patients with RA, 247 patients with SLE, and 178 controls contributed valid data for this analysis. A detailed description of clinical and sociodemographic data of the samples is displayed in Table 1.

As expected from the known female-to-male ratio in IRD, predominantly women participated in this study. Patients with RA were older than those with SLE; controls ranged in-between. In all groups, a majority of participants reported a nonacademic training background.

Both groups of patients reported more comorbidities than controls; however, in addition to lipometabolic disorder and osteoarthritis in patients with RA, arterial hypertension was the most frequent disease reported in all groups. Functional disability, as measured by the transformed HAQ values indicating physical limitations, was highest in patients with RA.

At time of reporting, $57.9 \%$ of the patients with SLE took at least 1 immunosuppressive drug (range 1-3); 41.3\% received glucocorticosteroids $(\mathrm{GC}) \leq 7.5 \mathrm{mg} /$ day and $16.2 \%$ $>7.5 \mathrm{mg} / \mathrm{day}$, and $33.6 \%$ took nonsteroidal antiinflammatory drugs (NSAID). In RA, 73.7\% of the patients received at least

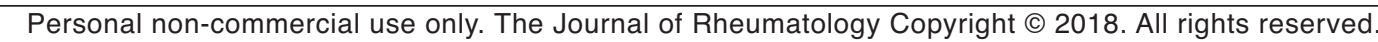


1 disease-modifying antirheumatic drug (DMARD; range $0-6), 43.3 \%$ took GC $\leq 7.5 \mathrm{mg} /$ day and $9.3 \%>7.5 \mathrm{mg} /$ day, and $63.3 \%$ were taking an NSAID. Controls reported NSAID intake in $1.1 \%$ and $\mathrm{GC} \leq 7.5 \mathrm{mg} /$ day in $0.6 \%$, while none took DMARD or GC $>7.5 \mathrm{mg} /$ day.

Representativeness of the patient groups. When comparing the patients of our RA and SLE samples to reference data of the NDB of the same calendar years, the proportion of women was $6-11 \%$ higher than in the NDB, while age and BMI were similar. Our patients had a somewhat longer disease duration and tended to have more comorbidities and more functional limitation than was the case in the NDB. Because women were slightly overrepresented in our study group, full-time employment was less frequent compared to the NDB. However, differences in professional education were small (Table 1). Our RA and SLE patients were significantly more often white-collar workers than those in the corresponding NDB groups (Table 1).

Scores of the 3 ERI scales and related internal consistency. Medians and IQR for the scores of the ERI scales are presented in Table 2. The levels of effort, E/R ratio, and overcommitment were significantly higher whereas the levels of reward were lower in the RA and SLE patient groups than in those in the control group.

Cronbach's alpha coefficients for the ERI questionnaire items are presented in Table 3. As can be seen, values consistently beyond a threshold of 0.70 indicate satisfactory internal consistency of the scales in all groups.

Construct validity and the factorial structure. Table 4 presents the structural validity of the ERI measure across all groups (complete, control, RA, SLE groups, respectively). As conceptually assumed, a third-order model representing an optimal structure of the theoretical ERI model fitted with the construct and structural validity, with acceptable values of GFI, AGFI, RMSEA, and CFI ( $>0.80)$. In addition, Figure 1 displays the factor loadings of all ERI items by CFA in the complete group. The pattern of factorial structure was found to be similar in the control, the RA, and the SLE groups (respective figures for the 3 groups are displayed in Supplementary Figure 1, available with the online version of this article).

\section{DISCUSSION}

To our knowledge, this is the first study measuring psychosocial stress at work in patients with SLE and RA who were capable of participating in regular work. Our results fill in an important gap of knowledge because both patient samples showed elevated psychosocial stress at work, reflected by significantly higher levels of effort, E/R ratio, overcommitment, and lower levels of reward in patients compared to respective levels in the control group.

Validated measures of a health-adverse psychosocial work environment are of high practical relevance in these samples, given a still-limited work participation among patients with IRD even when compared to the (German) general population in a male/female division, and given the effect of work on patients' life satisfaction and well-being $28,29,30$. This need becomes even more evident in the context of today's increasing work pressure, often combined with inappropri-

Table 2. Medians (IQR) of the ERI scales in the complete group, control group, patients with RA, and patients with SLE.

\begin{tabular}{lcccc}
\hline Scales & $\begin{array}{c}\text { Complete Group, } \\
\mathrm{n}=695\end{array}$ & $\begin{array}{c}\text { Control Group, } \\
\mathrm{n}=178\end{array}$ & $\begin{array}{c}\text { Patients with RA, } \\
\mathrm{n}=270\end{array}$ & $\begin{array}{c}\text { Patients with SLE, } \\
\mathrm{n}=247\end{array}$ \\
\hline Effort (E) & $15.00(12-18)$ & $14.00(12-16)$ & $16.00(12-19)^{* *}$ & $15.00(12-19)^{*}$ \\
Reward (R) & $47.00(40-52)$ & $48.00(42-52)$ & $47.00(38-51)^{*}$ & $46.00(40-51)$ \\
E/R ratio & $0.60(0.45-0.80)$ & $0.54(0.43-0.69)$ & $0.65(0.46-0.88)^{* *}$ & $0.61(0.48-0.83)^{* *}$ \\
Overcommitment & $13.00(11-17)$ & $12.00(10-15)$ & $14.00(11-17)^{* *}$ & $14.00(11-17)^{* *}$ \\
\hline
\end{tabular}

Differences were examined by Kruskal-Wallis test. Compared to the control group, $* \mathrm{p}<0.05$, ** $\mathrm{p}<0.01$ (pairwise 2-sided multiple comparison analyses were determined by Dwass, Steel, Critchlow-Fligner method). IQR: interquartile range; ERI: Effort-Reward Imbalance questionnaire; RA: rheumatoid arthritis; SLE: systemic lupus erythematosus.

Table 3. Cronbach's alpha coefficients of the ERI scales in the complete group, control group, patients with RA, and patients with SLE.

\begin{tabular}{lcccc}
\hline Scales & $\begin{array}{c}\text { Complete Group, } \\
\mathrm{n}=695\end{array}$ & $\begin{array}{c}\text { Control Group, } \\
\mathrm{n}=178\end{array}$ & $\begin{array}{c}\text { Patients with RA, } \\
\mathrm{n}=270\end{array}$ & $\begin{array}{c}\text { Patients with SLE, } \\
\mathrm{n}=247\end{array}$ \\
\hline Effort & 0.76 & 0.71 & 0.78 & 0.74 \\
Reward & 0.85 & 0.81 & 0.87 & 0.85 \\
Overcommitment & 0.78 & 0.80 & 0.76 & 0.79 \\
\hline
\end{tabular}

RA: rheumatoid arthritis; SLE: systemic lupus erythematosus; ERI: Effort-Reward Imbalance questionnaire. 
Table 4. Summary of goodness of fit for confirmatory factor analyses of the ERI questionnaire in the complete group, control group, patients with RA, and patients with SLE.

\begin{tabular}{lcccc}
\hline Fit Indices & $\begin{array}{c}\text { Complete Group, } \\
\mathrm{n}=695\end{array}$ & $\begin{array}{c}\text { Control Group, } \\
\mathrm{n}=178\end{array}$ & $\begin{array}{c}\text { Patients with RA, } \\
\mathrm{n}=270\end{array}$ & $\begin{array}{c}\text { Patients with SLE, } \\
\mathrm{n}=247\end{array}$ \\
\hline GFI & 0.89 & 0.84 & 0.84 & 0.84 \\
AGFI & 0.86 & 0.80 & 0.80 & 0.80 \\
RMSEA & 0.07 & 0.06 & 0.07 & 0.07 \\
CFI & 0.87 & 0.88 & 0.86 & 0.85 \\
\hline
\end{tabular}

ERI: Effort-Reward Imbalance questionnaire; RA: rheumatoid arthritis; SLE: systemic lupus erythematosus; GFI: goodness-of-fit index; AGFI: adjusted GFI; CFI: comparative fit index; RMSEA: root mean square error of approximation.

ately low wages and reduced job security, as well as in the context of rheumatic patients' known work incapacity rates in the labor market ${ }^{28}$. Because stress at work - measured by the ERI - significantly increases the risk for premature retirement and distinct stress-related physical and mental disorders, preventive measures are required at an early stage of chronic disease development ${ }^{31,32}$.

The ERI questionnaire, developed for comparative socioepidemiologic investigations of work-related stress, has been evaluated widely in different settings and in various languages ${ }^{33,34}$. Although its application to samples with chronic diseases has been less frequently reported to date, in this cross-sectional study we successfully applied the ERI model to patients with IRD. We demonstrated satisfactory psychometric properties of the 3 model scales in the complete study population, as well as in the 2 disease groups and in the healthy control group. Importantly, the 2 disease subgroups represent typical German RA and SLE patient groups, as confirmed by their comparison with the national database of the German Collaborative Arthritis Centers (Table 1).

Our CFA showed that the theoretical structure of the ERI model was well reproducible by a third-order model, which was the case for all groups. Internal consistency of the scales (Cronbach's alpha coefficients) was satisfactory, ranging from 0.71 to 0.85 . While meeting the required criteria, the psychometric properties concerning construct validity and the factorial structure were somewhat lower than those previously documented for healthy population groups ${ }^{17,18,19,20,21,22,23,24,25}$. The psychometric properties in our study were also less pronounced than those reported in one of the few investigations of a working population with chronic disease, the Canadian survey of 814 post-myocardial infarction patients who had returned to work ${ }^{11}$. However, a direct comparison of the data from the 2 studies of ERI among workers with cardiovascular diseases with data from our study was not feasible, because of different ERI measures (specifically, different numbers of scale items) between the 2 studies. Yet it is of interest that effort, reward, and E/R ratio were all associated with psychological distress among post-myocardial infarction patients from Canada ${ }^{11}$. Similarly, a study comparing work stress between patients with cardio- vascular diseases and healthy controls in China and Australia found higher levels of stressful work through the ERI model among the former group ${ }^{12}$. These findings support the notion that people with chronic disease exhibit a higher burden of disease than those who are free from such disorders.

Limitations. Even though our study samples represent major characteristics of patients with RA and SLE from the national database in Germany, further studies with larger sample sizes, more male patients, and higher percentages of blue-collar workers are required to support and confirm our findings. Because our proxy strategy led to a control group with fewer comorbidities than the patient groups, it needs to be taken into account that the stress at work might also be influenced by the comorbidities. Because we tested the ERI questionnaire in a cross-sectional study, we were not able to assess whether ERI at work is prospectively associated with an increased risk of any new comorbidity in patients with SLE and/or RA. In addition, given a restricted sample size, we provide relatively crude results, without specifying them according to occupational categories, socioeconomic subgroups reflecting social inequities, disease duration, immunosuppressive treatment groups, or comorbidities. Another constraint of the study is the self-reported character of data about patients' rheumatic diseases, because no information on physician-confirmed diagnoses was available. However, studies show that self-reported SLE and RA have reasonable sensitivity and specificity, with acceptable agreement to medically certified records ${ }^{35,36}$. Finally, the procedure of selecting control participants through self-recruitment of patients does not conform to established quality criteria of recruiting control subjects in clinical or epidemiological studies, but was a realistically available proxy strategy to contrast data of the 2 disease groups with those of a similar, otherwise healthy group of working people. It remains speculative why the participants did not support the proxy strategy sufficiently, because most of the patients had informed their employers and colleagues about their IRD.

Implications. Our results call for measures of disease-specific improvement of employed persons with SLE and/or RA that can only be reached by the collaboration and integration of

Personal non-commercial use only. The Journal of Rheumatology Copyright @ 2018 . All rights reserved. 


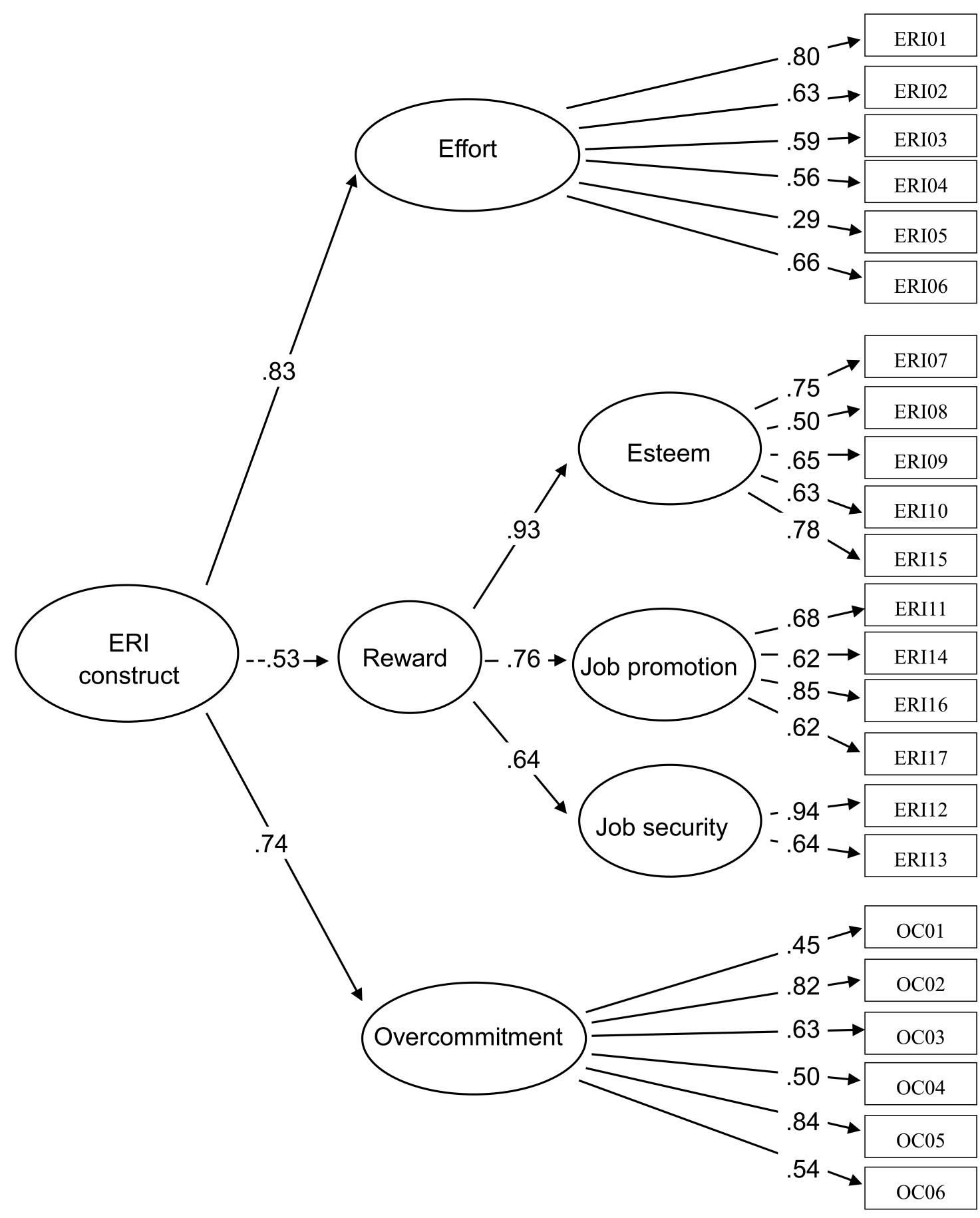

Figure 1. Confirmatory factor analysis testing the theoretical construct underlying the Effort-Reward Imbalance (ERI) questionnaire in the complete group.

people from diverse disciplines (e.g., patients, general practitioners, rheumatologists, occupational physicians, and employers). Collaborative work on improvement of the perceived working life factors and the related distress might lead to enhanced patient (life) satisfaction and well-being. Study of psychosocial stress and its confounding disease-associated factors (e.g., disease activity, medication, damage, and additional sociodemographic variables such as social status) is now trustworthy and feasible in these diseases. Addressing these interactions might be relevant for the patients and their practicing rheumatologists to improve patient care and work satisfaction.

Patients with SLE and RA showed elevated psychosocial stress at work compared to controls, thus offering room for 
improvement by the integration and collaboration of others involved. Despite the given limitations and some heterogeneity of the sample, we demonstrated convincing performance and appropriate psychometric properties of the ERI questionnaire, an internationally established measure of psychosocial stress at work, in patients with SLE and RA who are capable of work. This measure can therefore be recommended as a useful tool for application in clinical and epidemiological studies. Further investigations, especially those applying multiple longitudinal measurements, are warranted to strengthen this recommendation.

\section{ACKNOWLEDGMENT}

Data entry was supported by Martina Kümmel, Mia Vidakovic, and Nicole Hoffmann.

\section{ONLINE SUPPLEMENT}

Supplementary material accompanies the online version of this article.

\section{REFERENCES}

1. Gordon C, Isenberg D, Lerstrøm K, Norton Y, Nikaï E, Pushparajah DS, et al. The substantial burden of systemic lupus erythematosus on the productivity and careers of patients: a European patient-driven online survey. Rheumatology 2013;52:2292-301.

2. Lacaille D, White MA, Backman CL, Gignac MA. Problems faced at work due to inflammatory arthritis: new insights gained from understanding patients' perspective. Arthritis Rheum 2007; 57:1269-79.

3. de Jong M, de Boer AG, Tamminga SJ, Frings-Dresen MH. Quality of working life issues of employees with a chronic physical disease: a systematic review. J Occup Rehabil 2015;25:182-96.

4. Schnall PL, Dobson M, Rosskam E, Baker D, Landsbergis P, editors. Unhealthy work: causes, consequences and cures. Amityville, NY: Baywood Press; 2008.

5. Gignac MA, Backman CL, Kaptein S, Lacaille D, Beaton DE, Hofstetter C, et al. Tension at the borders: perceptions of role overload, conflict, strain and facilitation in work, family and health roles among employed individuals with arthritis. Rheumatology 2012;51:324-32.

6. Utset TO, Baskaran A, Segal BM, Trupin L, Ogale S, Herberich E, et al. Work disability, lost productivity and associated risk factors in patients diagnosed with systemic lupus erythematosus. Lupus Sci Med 2015;2:e00058.

7. Baker K, Pope J. Employment and work disability in systemic lupus erythematosus: a systematic review. Rheumatology 2009;48:281-4.

8. Mancuso CA, Rincon M, Sayles W, Paget SA. Longitudinal study of negative workplace events among employed rheumatoid arthritis patients and healthy controls. Arthritis Rheum 2005;53:958-64.

9. Siegrist J. Adverse health effects of high-effort/low-reward conditions. J Occup Health Psychol 1996;1:27-41.

10. Siegrist J, Wahrendorf M, editors. Work stress and health in a globalized economy: The model of effort-reward imbalance. Cham, Switzerland: Springer International Publishing; 2016.

11. Aboa-Éboulé C, Brisson C, Blanchette C, Maunsell E, Bourbonnais $\mathrm{R}$, Abdous B, et al. Effort-reward imbalance at work and psychological distress: a validation study of post-myocardial infarction patients. Psychosom Med 2011;73:448-55.

12. Li J, Dollard MF, Loerbroks A, Angerer P. Cardiovascular disease is associated with the perception of worsening psychosocial work characteristics. Int J Cardiol 2015;186:149-51.

13. Zink A, Huscher D, Schneider M. [The National Database of the German Arthritis Centres-a 12 year balance]. [Review in German]
Z Rheumatol 2006;65:144, 146-51.

14. Albrecht K, Huscher D, Eidner T, Kleinert S, Späthling-Mestekemper $\mathrm{S}$, Bischoff $\mathrm{S}$, et al. [Medical treatment of rheumatoid arthritis in 2014: Current data from the German Collaborative Arthritis Centers]. [Article in German] Z Rheumatol 2017;76:50-7.

15. Fischer-Betz R, Wessel E, Richter J, Winkler-Rohlfing B, Willers R, Schneider M. Lupus in Germany: analysis within the German lupus self-help organization (LULA). Z Rheumatol 2005;64:111-22.

16. Lautenschläger J, Mau W, Kohlmann T, Raspe HH, Struve F, Brückle W, et al. [Comparative evaluation of a German version of the Health Assessment Questionnaire and the Hannover Functional Capacity Questionnaire]. [Article in German] Z Rheumatol 1997;56:144-55.

17. Siegrist J, Starke D, Chandola T, Godin I, Marmot M, Niedhammer I, et al. The measurement of effort-reward imbalance at work: European comparisons. Soc Sci Med 2004;58:1483-99.

18. Leineweber C, Wege N, Westerlund H, Theorell T, Wahrendorf M, Siegrist J. How valid is a short measure of effort-reward imbalance at work? A replication study from Sweden. Occup Environ Med 2010;67:526-31.

19. Hanson EK, Schaufeli W, Vrijkotte T, Plomp NH, Godaert GL. The validity and reliability of the Dutch Effort-Reward Imbalance Questionnaire. J Occup Health Psychol 2000;5:142-55.

20. Niedhammer I, Siegrist J, Landre MF, Goldberg M, Leclerc A. [Psychometric properties of the French version of the Effort-Reward Imbalance model]. [Article in French] Rev Dépidémiologie Santé Publique 2000;48:419-37.

21. Weyers S, Peter R, Boggild H, Jeppesen HJ, Siegrist J. Psychosocial work stress is associated with poor self-rated health in Danish nurses: a test of the effort-reward imbalance model. Scand J Caring Sci 2006;20:26-34.

22. Li J, Yang W, Cheng Y, Siegrist J, Cho S-I. Effort-reward imbalance at work and job dissatisfaction in Chinese healthcare workers: a validation study. Int Arch Occup Environ Health 2005;78:198-204.

23. Li J, Loerbroks A, Shang L, Wege N, Wahrendorf M, Siegrist J. Validation of a short measure of effort-reward imbalance in the workplace: evidence from China. J Occup Health 2012;54:427-33.

24. Tsutsumi A, Ishitake T, Peter R, Siegrist J, Matoba T. The Japanese version of the effort-reward-imbalance questionnaire: a study in dental technicians. Work Stress 2001;15:86-96.

25. Li J, Loerbroks A, Jarczok MN, Schöllgen I, Bosch JA, Mauss D, et al. Psychometric properties and differential explanation of a short measure of effort-reward imbalance at work: a study of industrial workers in Germany. Am J Ind Med 2012;55:808-15.

26. Cuesta MJ, Peralta V. Thought disorder in schizophrenia. Testing models through confirmatory factor analysis. Eur Arch Psychiatry Clin Neurosci 1999;249:55-61.

27. Someya T, Sakado K, Seki T, Kojima M, Reist C, Tang SW, et al. The Japanese version of the Barratt Impulsiveness Scale, 11th version (BIS-11): its reliability and validity. Psychiatry Clin Neurosci 2001;55:111-4.

28. Mau W, Thiele K, Lamprecht J. [Trends of work force participation of patients with rheumatic diseases: results from German social insurance data and the national database of the German collaborative arthritis centers]. [Article in German] Z Rheumatol 2014;73:11-9.

29. Gignac MA, Cao X, Tang K, Beaton DE. Examination of arthritis-related work place activity limitations and intermittent disability over four-and-a-half years and its relationship to job modifications and outcomes. Arthritis Care Res 2011;63:953-62.

30. Robinson D, Aguilar D, Schoenwetter M, Dubois R, Russak S, Ramsey-Goldman R, et al. Impact of systemic lupus erythematosus on health, family, and work: the patient perspective. Arthritis Care Res 2010;62:266-73. 
31. Hintsa T, Kouvonen A, McCann M, Jokela M, Elovainio M, Demakakos P. Higher effort-reward imbalance and lower job control predict exit from the labour market at the age of 61 years or younger: evidence from the English Longitudinal Study of Ageing. J Epidemiol Community Health 2015;69:543-9.

32. Rugulies R, Aust B, Madsen IE. Effort-reward imbalance at work and risk of depressive disorders. A systematic review and meta-analysis of prospective cohort studies. Scand J Work Environ Health 2017;43:294-306.

33. Tsutsumi A, Kawakami N. A review of empirical studies on the model of effort-reward imbalance at work: reducing occupational stress by implementing a new theory. Soc Sci Med 2004; 59:2335-59.
34. van Vegchel N, de Jonge J, Bosma H, Schaufeli W. Reviewing the effort-reward imbalance model: drawing up the balance of 45 empirical studies. Soc Sci Med 2005;60:1117-31.

35. Walitt BT, Constantinescu F, Katz JD, Weinstein A, Wang H, Hernandez RK, et al. Validation of self-report of rheumatoid arthritis and systemic lupus erythematosus: The Women's Health Initiative. J Rheumatol 2008;35:811-8.

36. Peeters GM, Alshurafa M, Schaap L, de Vet HC. Diagnostic accuracy of self-reported arthritis in the general adult population is acceptable. J Clin Epidemiol 2015;68:452-9. 